\title{
Cervical Pap smear Screening: Is it really useful in Indian scenario?
}

\author{
Patel NP', Gedam DS ${ }^{2}$ \\ ${ }^{1}$ Dr Narmada Prasad Patel $\&{ }^{2}$ Dr D Sharad Gedam, Both are affiliated with L N Medical College, Bhopal, India \& are \\ member of Editorial board, IJMRR
}

Address for correspondence: Dr Narmada Prasad Patel, Email, narmadapatel2006@rediffmail.com

\begin{abstract}
:
Cervical cancer is the leading cancer in women in India and worldwide. It is unique in providing long window period amenable for early detection in precancerous state through suitable screening tools. Pap smear remain important screening modality. Proper selection of screening method in community setting is a matter of debate.
\end{abstract}

Key words: Cervical cancer screening, Pap smear, Cervical intraepithelial neoplasia (CIN), Human papilloma virus(HPV)

Cervical cancer is the commonest cancer in women worldwide. ${ }^{1}$ This is responsible for huge healthcare burden in terms of morbidity and mortality in both developed and underdeveloped world countries. With the better treatment of communicable disease, India is heading towards a major epidemic related to noncommunicable disease including cancers. Cervical cancer remain leading cause of cancer in women in India, accounting for nearly $25.9 \%$ of new cancer cases and $23.3 \%$ of all cancer-related deaths in the country. ${ }^{2}$ In 2008 in India, the annual incidence and mortality from cervical cancer was 134,420 cases and 72,825 deaths, respectively. In view of the huge population burden and limited healthcare resources, we have to look for the various ways of cost effective preventive and treatment modalities.

Cervical cancer screening is an important tool in prevention and early treatment because of window of opportunity during the long standing pathogenesis of the cervical cancer. ${ }^{3}$ Cervical cancer results from a persistent infection by a highrisk subset of human papillomavirus (HPV). ${ }^{4}$ Most women's immune systems will eliminate HPV infection spontaneously, however, for a very small proportion of women, the infection will persist and can cause precancerous changes in cells. In the precancerous state ie Cervical intraepithelial neoplasia (CIN) occurs along various grades from low (CIN1), moderate (CIN2) to severe (CIN3). The pathogenesis from low-grade $\mathrm{CIN}$ to cervical cancer takes from 10 to 20 years, during which timely screening for pre-cancerous lesions and early treatment is highly effective in preventing overt disease. Cervical cancer screening using various methods including Pap test (cytology), visual inspection with acetic acid (VIA), with Lugol's iodine (VILI), and the HPV-DNA test has been shown to be effective screening methods. Traditionally pap smear has remained the corner stone of cervical cancer screening programs globally and in India up till now. The evidence of pap smear's efficacy and utility is largely based on the results from the developed countries where this screening tool has resulted in definitive decrease in overall incidence and disease burden. But when it comes to the countries from developing world especially Indian contest, the overall efficacy becomes questionable because of variety of technical and social factors responsible for the same. Hence forth we need to judge the efficacy and practical utility of various alternative screening methods available to us and review our health policies targeted to screen and prevent the leading cancer cause in Indian woman.

Pap smear is a cytology based screening tool in which we need to have a dedicated staff which at least include a nurse or doctor to collect the sample, a cytotechnician to process and analyze the smear and a pathologist to confirm a positive finding on biopsy. If a smear turn out to be positive then the female is required to be traced, notified and then referred to further investigation and treatment. This whole process requires long time involving smear collection, processing and positive reporting, subsequent investigation and treatment. This requires multiple visits and complex process to follow for the successful outcome of the overall preventive program. These act as major hurdle in the whole program in developing country such as India. Moreover the cytology based screening program has got poor sensitivity in developing countries as compared to developed countries ie $26-65 \%$ and $53 \%$ respectively in CIN 2 and CIN 3. ${ }^{5-7}$ This poor sensitivity has been improved by organized repeated testing in developed countries and this is the reason for success of the program. The methods such as visual inspection with acetic acid(VIA) involves inspection of the cervix with the naked eye, one to two minutes after the application of 3-5\% acetic acid under adequate light and white areas in or near transformation zone (TZ) are considered positive. The sensitivity of these method is comparable or greater than the pap smear ie $41 \%$ to $79 \%$ for VIA. ${ }^{5,8-10}$ and $57 \%$ to $98 \%$ for VILI. ${ }^{11,12}$ The VIA is feasible in underdeveloped world setting and is also efficient. This can give instant result which may be amenable to treatment in the same visit. However this method has got drawback in the form of being unreliable in postmenopausal women due to inward recession of transformation zone. A more effective, reliable although more expensive is method HPV 


\section{Editorial}

DNA testing. This uses cervical or vaginal samples, obtained with a brush instead of a swab. The samples are collected either by a trained provider or, in the case of vaginal sampling, by the woman herself making it more acceptable. HPV-testing samples are processed with the use of the Hybrid Capture 2 assay for 13 high-risk HPV types. The sensitivity of HPV-DNA for detecting CIN 2-3 ranges from $66-95 \%$ with most studies reporting values greater than $85 \%$ among women 30 years or older.,11,13 This method also overcome the drawback associated with VIA in post menopausal woman. The cost involved remains major obstacle in the deployment of this test in Indian contest. As we move ahead for better health, cervical cancer screening is one of the basic right of every woman. We need to improve the quality of interventions that we have directed toward the early detection and treatment of cervical cancer. Apart from the technical intervention, many other factors such as awareness, education and attitude of the health care worker and the target population make great impact on the results of the screening interventions. As of now all the three methods seems good enough for different subset of population, considering their cost, efficacy, feasibility and availability. Pap smear has remained the oldest tool for screening of the cervical cancer, also it's success has been documented over past many decades in developed world, we may try to improve the coordinated team work and it's availability to large target population so as to achieve the expected benefit in community setting. VIA and VILI seems to be promising in premenopausal woman and this may be implemented in phased manner to assess the applicability and overall success in community setting. Vaccination for common HPV strains responsible for the cancer can also be a reasonably good strategy for prevention of cervical cancer and can prove to be effective in spreading awareness for the disease. Strategies targeting at awareness and prevention will be beneficial not only for cervical cancer but also for overall health of the community. Gangwani et $\mathrm{al}^{14}$ studied pap smear screening in his study. He could have compare with other screening methods. Small sample size was other important limitation of his study.

\section{References}

1. World Health Organization (2009) 'The global burden of disease: Death and DALY estimates for 2004 by cause for WHO member States, 2004 Update.' WHO: Geneva. cited 2014 Feb 26.Available from:www.who.int/healthinfo/ global_burden_disease/GBD_report_2004updat

2. Ferlay J, Shin HR, Bray F, Forman D, Mathers C, Parkin DM. GLOBOCAN 2008 v1.2: Cancer incidence and mortality worldwide: IARC CancerBase No. 10. Lyon (France): IARC Press; 2010. Available from: http:// globocan.iarc.fr.Accessed: Feb 26, 2014
3. Cole P, Morrison AS. Basic issues in population screening for cancer. J Natl Cancer Inst. 1980 May;64(5): 1263-72.

4. Walboomers JM, Jacobs MV, Manos MM, Bosch FX, Kummer JA, Shah KV, Snijder PJ, Peto J, Meijer CJ, Munoz N. Human papillomavirus is a necessary cause of invasive cervical cancer worldwide. J Pathol.1999 Sep; 189(1): 12-19 5. Almonte M, Ferreccio C, Winkler JL, Cuzick J, Tsu V, Robles, Takahashi R, Sasieni P. Cervical screening by visual inspection, HPV testing, liquid-based and conventional cytology in Amazonian Peru. Int J Cancer. 2007 Aug; 121(4): 796-802.

6. Cuzick J, Clavel C, Petry KU, Meijer CJ, Hoyer H, Ratnam S, Szarewski A, Birembaut P, Kulasingam S, Sasieni P, Iftner T. Overview of the European and North American studies on HPV testing in primary cervical cancer screening. Int J Cancer. 2006 Sep 1; 119(5): 1095-101.

7. Sankaranarayanan R, Thara S, Sharma A, Roy C, Shastri S, Mahe C, Muwonge R, Fontaniere B. Accuracy of conventional cytology: results from a multicentre screening study in India. J Med Screen. 2004; 11(2): 77-84.

8. Belinson J, Qiao Y, Pretorius R, Zhang W, Keaton K, ElsonP, Fischer C, Lorincz A, Zahniser D, Wilbur D, Pan Q, Li L, Biscotti C, Dawson A, Li A, Wu L, Ling Y, Ma CP, Yang CP. Prevalence of cervical cancer and feasibility of screening in rural China: a pilot study for the Shanxi Province Cervical Cancer Screening Study. Int J Gynecol Cancer.1999 Sep; 9(5): 411-7.

9. Megevand E, Denny L, Dehaeck K, Soeter R, Bloch B. Acetic acid visualization of the cervix: an alternative to cytologic screening. Obstet Gynecol. 1996 Sep; 88(3): 383-6. 10. Sauvaget C, Fayette JM, Muwonge R, Wesley R, Sankarnarayanan R. Accuracy of visual inspection with acetic acid for cervical cancer screening. Int $J$ Gynaecol Obstet. 2011 April; 113(1): 14-24.

11. Sankaranarayanan R, Gaffikin L, Jacob M, Wesley R, Sellers J, Robles S. A critical assessment of screening methods for cervical neoplasia. Int J Gynaecol Obstet. 2005 May; 89 Suppl 2: S4-S12.

12. Muwonge R, Manuel MG, Filipe AP,Dumas JB, Frank MR, Sankarnarayanan R. Visual screening for early detection of cervical neoplasia in Angola. Int $J$ Gynaecol Obstet. 2010 Oct; 111(1): 68-72.

13. Qiao YL, Sellors JW, Eder PS, Bao YP, Lim JM, Zhao FH, Weigl b, Zhang WH, Peck RB, Li L, Chen F, Pan QJ, Lorincz AT. A new HPV-DNA test for cervical-cancer screening in developing regions: a cross-sectional study of clinical accuracy in rural China. Lancet Oncol. 2008 Oct; 9(10): 929-36.

14. Gangwani A, Shrivastava R. Study of Cervical Pap Smears in central India: a city based study. Int $J$ Med Res Rev2014;2(1):53-5

\section{How to cite this article?}

Patel NP, Gedam DS. Cervical Pap Smear Screening: Is it really useful in Indian scenario? Int J Med Res Rev 2014;2(1):1-2. 10.17511/ijmrr.2014.i01.01 